\title{
Drive Cycle Performance of Hybrid-Electric Vehicles
}

\author{
Godwin Kafui Ayetor, George Bright Gyamfi, Ebenezer Tetteh Larnor \\ Department of Automotive Engineering, Koforidua Polytechnic, P.O. Box 981, Koforidua, Ghana \\ Email:kafuiayetor@yaboo.co.uk,gbggem@yaboo.com,ebenlart@yahoo.com
}

\begin{abstract}
This paper focuses on the effects of HEV (Hybrid-Electric Vehicles) Powertrains on fuel economy and overall system efficiency. Three different hybrid-electric powertrains: Series; Parallel and Combined have been simulated on ADVISOR by the use of MATLAB platform. Three drive cycles, Urban Dynamometer Driving Schedule (UDDS), New European Driving Cycle (NEDC) and Highway Fuel Economy Transport Cycle (HWFET), were used to determine best Fuel Economy, Overall System Efficiency and Energy usage for each Powertrain. While Parallel Powertrain showed best fuel economy and system efficiency at lower speeds $(20 \mathrm{mph})$ during frequent start-stops, Combined Hybrid showed much more significant fuel savings at constant speeds above-48 $\mathrm{mph}$. In situations where both battery and engine power were required simultaneously, Combined Hybrid showed much higher system efficiency giving credence to its PowerSplit device. In conclusion, the selection of the preferred Powertrain for Hybrid Electric application depends strictly on the application required. The results clearly show that advantages of both Series and Parallel powertrains have not been effectively harnessed in the Combined Powertrain as expected. This highlights the need for a Powertrain which effectively saves fuel at all speeds irrespective of number of idle times or stops.
\end{abstract}

Keywords: Hybrid electric vehicle; zero emissions; combined hybrid; series hybrid; parallel hybrid; electric vehicles; fuel cells

\section{Introduction}

Instead of comparing strength and weaknesses of existing HEV powertrains, most research papers focus on building newer powertrains comparing their benefits over conventional vehicles. Meisel Jerome (2006) highlights the advantages of the Toyota hybrid system over conventional vehicles but fails to mention how it differs from other hybrid powertrains. Chachra and Bhartendu (2008) mention inefficiencies of Series and Combined hybrids but falls short of when these inefficiencies occur. The choice of a Hybrid topology is strongly dependent on the application (EudeCezarand, 2006). This research attempts to determine the best HEV (Hybrid Electric Vehicle) Powertrain topology in terms of fuel economy, emissions and overall system efficiency over different drive cycles.

Ever rising crude oil prices and stricter standard emission regulations have put a lot of pressure on automotive manufacturers to produce more fuel efficient and zero emission cars. The development of Powertrain systems for automotive vehicles with higher fuel efficiency and less emissions without sacrificing high performance level is an enormous challenge to the automotive industry (Kluger et. al, 2001). By combining benefits of electric vehicles and conventional vehicles, hybrid electric vehicles are known to produce almost zero emissions, low noise, and faster responses hence are more reliable (EudeCezarand, 2006). A hybrid electric vehicle is described as one with two energy storage systems both of which must provide propulsion together or independently (Tate et.al, 2008). The sources of propulsion have both conventional IC engine or fuel cells and electric motors. There are approximately 40 various viable hybrid topologies each with specific advantages and drawbacks (Hiltech, 2006).

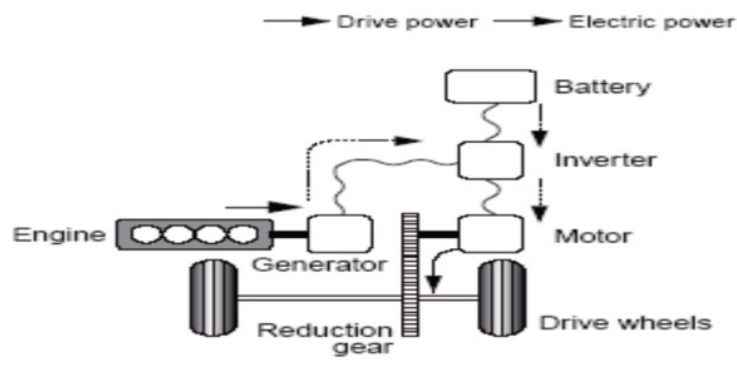

Fig.1: Series Powertrain (courtesy Toyota Motor Corp.) 
All the topologies are somewhat variants of Series and Parallel hybrids. In series configuration, the main purpose of IC engine is to charge the batteries by supplying the generator with mechanical energy (Kluger et.al 2001). The energy flow is as depicted in fig.1. Mechanical energy from the engine is transmitted to the generator for onward transmission to the battery as electrical energy. The generator is attached directly to the crankshaft to enable stop-start and regeneration (Chottiner et.al, 2002). The inverter makes it possible for the electrical energy (AC) from the generator to be converted to a DC before it can be stored in the battery and also from DC to AC when it is transmitted to the traction motor from the battery. In Parallel propulsion, power supplied by the gasoline engine and electric motor can be applied to move the wheels (Singer-Englar et.al, 2005). Where engine power is required, it is engaged by clutch in the transmission to spin the reduction gear (fig. 2). Where engine torque is not required, it is disengaged through the same clutch. Electric power can be applied independently from the battery through motor to gears to wheels. At higher acceleration demands, both engine and motor torques can be applied at the same time through the reduction gear.

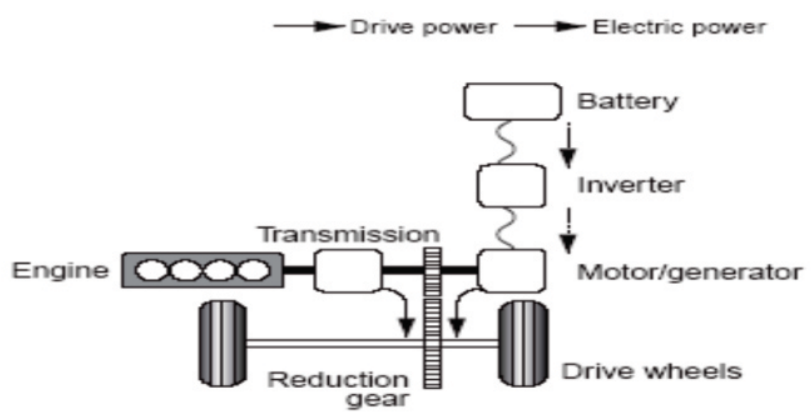

Fig.2: Parallel Powertrain (courtesy Toyota Motor Corp.)

The power split device made up of planetary gear set is what defines a combined Hybrid. This feature combines a series-parallel configuration that utilises advantages of both Powertrains (fig.3). It splits power from the engine into two routes: mechanical and electrical (Meisel, 2006). Planetary gear can transfer power between engine, motor, generator, and wheels in almost any combination. Just like Parallel type both engine and motor can apply torque independently to move the wheels.

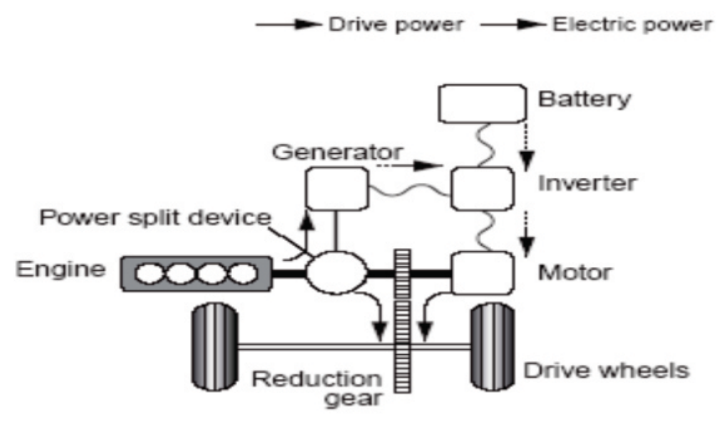

Fig.3: Combined hybrid (courtesy Toyota Motor Corp.)

\subsection{ADVISOR simulation tool}

ADVISOR is a drivetrain analysis tool developed in MATLAB/Simulink ${ }^{\circledR}$ to compare fuel economy and emission performance between different drivetrain configurations. National Renewable Energy Laboratory (NREL) first developed the Advanced Vehicle Simulator, ADVISOR, in November 1994(Wikpe and Cuddy, 1999). It was designed as an analysis tool to assist the U.S. Department of Energy (DOE) in developing and understanding hybrid electric vehicles (HEVs) through the Hybrid Vehicle Propulsion System contracts with Ford, GM, and Chrysler. The ADVISOR has also been used by many to understand the system-level interactions of hybrid and electric vehicle components. ADVISOR analyzes vehicle powertrains, focusing on power flows among components. ADVISOR is driven by the input driving profiles which can be the classic speed vs. time or a speed and grade vs. Time driving profile (Senger et.al, 1998). With a given driving profile goal, ADVISOR then works its way backwards from the required vehicle and wheel speeds to the required torques and speeds of each component between the wheels and the energy source. Limits for each of the components are included, so the actual speed vs. Time profile computed is the one that is within the limits of all components and includes all component losses and vehicle drag. ADVISOR has been applied to many different system analysis problems, such as the need of developing the SAE J1711 test procedure for hybrid vehicles and the need of evaluating new technologies as part of the Partnership for a New Generation of Vehicles (PNGV) technology selection process. The model has been benchmarked and validated with other models and with real vehicle test data.

\subsection{Toyota bybrid system powertrains}

In December 1997, the first mass produced hybrid 
system (THS Prius), Toyota Prius, was introduced into the Japanese market (Kondo et.al, 2002). In 2001, Toyota introduced the Estima and Crown Hybrids into the Japanese market. The Estima Hybrid is the world's first hybrid minivan and first mass-produced hybrid 4-wheel drive vehicle (Kondo et.al, 2002). Year 2002 marked the release of Toyota's fuel cell hybrid (Toyota FCHV) in Japan and America (Toyota Motor Corp, 2007). In 2003, Toyota completely redesigned the Prius ( second generation Prius) and integrated THS-II into the model. THS-II marketed as Hybrid Synergy Drive [HSD] with 1.5 litre 4 cylinder gasoline engine, was superior to THS in power performance (motor output 1.5 times Prius I), fuel economy and exhaust gas reduction performance (Kimura et.al, 2005). In 2005, “combined with a V6 engine, THS II had a further evolution as a Hybrid System for SUV, which was installed in the RX400h and Highlander Hybrid to be introduced into the world" (Kimura et.al, 2005). It achieved a fuel capacity of 1.5L. 2006, saw the hybrid synergy drive (HSD) being installed as a rear-wheel drive passenger vehicle in the LEXUS GS450h (Camry Hybrid) which is a hybrid version of the conventional Camry sedan. LEXUS GS450h achieved 4.5 litre classes and had outstanding fuel emission performance (UeokaKiyoshiro et.al, 2007). In 2007, the product range was further broadened; the HSD was expanded to a new LHD (Left Hand Drive) for AWD passenger cars. This is the LEXUS LS600hL with a V8 and 5.0L engine capacity. This system was designed to meet the requirements of the highest grade of LEXUS (UeokaKiyoshiro et.al, 2007).

According to the Toyota website, third generation Prius is already being marketed with a $90 \%$ new Powertrain developed. Total horsepower is 134 hp (previously $110 \mathrm{hp}$ ) and it has thirty-six Kyocera solar cells which are positioned on a moon roof and doubles as a sunroof. Energy is converted at a 16.5 efficiency rate to power the ventilation fan and air conditioning system with about 50 watts of electricity. It also has an impressive EPA 51/48/50 city/highway combined mpg estimate. It is more aerodynamic with the coefficient of drag reduced to $0.25 \mathrm{C}_{\mathrm{d}}$.

\section{Objectives}

Objective of the research is to

(a) Simulate and analyse performance of three hybrid electric powertrains namely Series, Parallel and Combined on the Matlab platform (ADVISOR). Simulations will be run for three drive cycles, namely, the Urban Dynamometer Drive Cycle (UDDC), New European Drive Cycle (NEDC) and the High Way Fuel Economy Cycle (HWFEC).

(b) Suggest the most suitable powertrains for different driving conditions.

\section{Methodology}

\subsection{Power train design parameters}

In order to make sure all other parameters remain the same except Powertrain configuration, Toyota Prius vehicle was chosen for each of the three Powertrains:

Actual Body Weigh $\mathrm{t}=2783$ pounds $(1398 \mathrm{~kg})$-full tank, Vehicle Cargo Mass $=136 \mathrm{~kg}$

Vehicle Coefficient of Drag $=0.3$, Vehicle Frontal Area $=1.746 \mathrm{~m}$

Fuel Type $=$ Gasoline, Capacity $=1.5 \mathrm{~L}$ Japan Prius Atkinson Cycle Engine

Maximum Power $=43 \mathrm{~kW}$ at $4000 \mathrm{RPM}$, Peak Torque $=75 \mathrm{lb}-\mathrm{ft}$ at $4000 \mathrm{RPM}$

Peak Efficiency $=0.39$, Weight $=137 \mathrm{~kg}$

Each had a Traction Motor with parameters:

Peak Efficiency $=0.91$, Mass $=57 \mathrm{~kg}, 30-\mathrm{kW}$ permanent magnet motor/controller

Accessories of 700-W constant electric load applied to each Powertrain.

Only Series and Combined Hybrids have additional Generator with the following parameters:

PRIUS_JPN15-kW permanent magnet motor/controller

Peak Efficiency $=0.84$, weight $=33 \mathrm{Kg}$

\subsection{Drive cycle characteristics}

Three drive cycles were used for the simulation.

1. Urban Dynamometer Driving Schedule (UDDS) which refers to United States Environmental Protection Agency mandated dynamometer test that represents city driving conditions was used for light duty vehicle testing (fig.4).

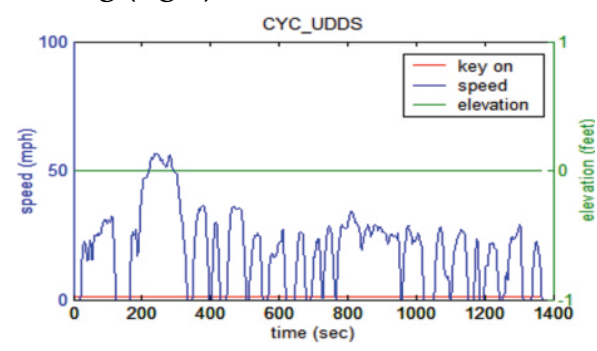

Fig.4: speed-time representation of UDDS cycle 
It is a speed-time trace consisting of 18 profiles separated by idle periods of $0-39 \mathrm{~s}$ duration and is used to validate economy and emissions of passenger cars(Miller, 2004). The schedule covers 7.46 miles in $1372 \mathrm{~s}$ for an average speed of $19.58 \mathrm{mph}$ (table 1 ).

Table 1

Characteristic values for UDDS cycle

\begin{tabular}{lr}
\hline Cycle & UDDS \\
\hline Time(s) & 1369 \\
Distance (miles) & 7.45 \\
Max. speed(mph) & 56.7 \\
Average speed(mph) & 19.58 \\
Max. acceleration $\left(\mathrm{ft} / \mathrm{s}^{2}\right)$ & 4.84 \\
Max. deceleration $\left(\mathrm{ft} / \mathrm{s}^{2}\right)$ & -4.84 \\
Idle times(s) & 259 \\
Number of stops & 17 \\
\hline
\end{tabular}

2. NEDC cycle is typically used to characterise hybrid vehicle economy and emissions (Miller, 2004). Fig. 5 and table 2 below represent the cycle with maximum speed $74.56 \mathrm{mph}$ and average of $20.64 \mathrm{mph}$ lasting 1184s.

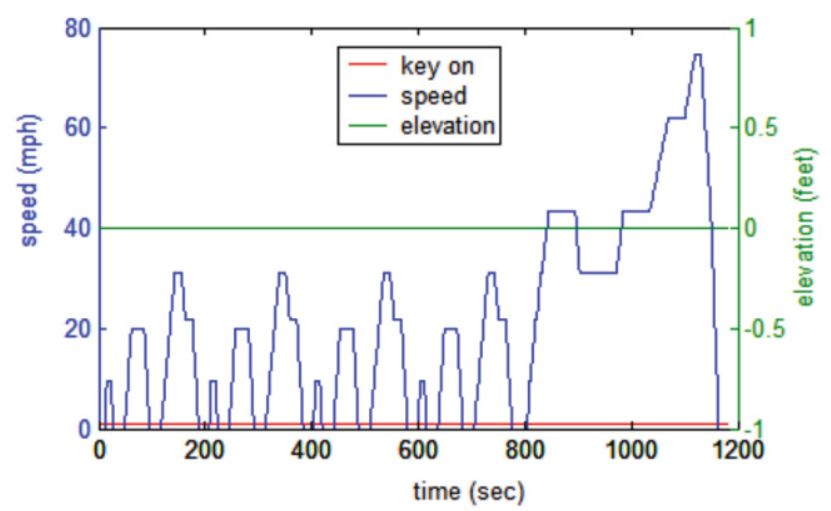

Fig.5: Speed-Time Graph representation for NEDC cycle

Table 2

Typical values for NEDC Cycle

\begin{tabular}{lr}
\hline Cycle & NEDC \\
\hline Time(s) & 1184 \\
Distance (miles) & 6.79 \\
Max. speed(mph) & 74.56 \\
Average speed $(\mathrm{mph})$ & 20.64 \\
Max. acceleration $\left(\mathrm{ft} / \mathrm{s}^{2}\right)$ & 3.46 \\
Max. deceleration $\left(\mathrm{ft} / \mathrm{s}^{2}\right)$ & -4.56 \\
Idle times(s) & 298 \\
Number of stops & 13 \\
\hline
\end{tabular}

EPA highway cycle depicts expressway driving wherethe traffic flow is smooth (Miller, 2004).As seen from fig.6, a constant overall speed exists for the highway cycle. The average speed of $48.2 \mathrm{mph}(77.57$ $\mathrm{kph}$ ) for 10.26 miles is higher than UDDS and NEDC drive cycles (table 3 ).

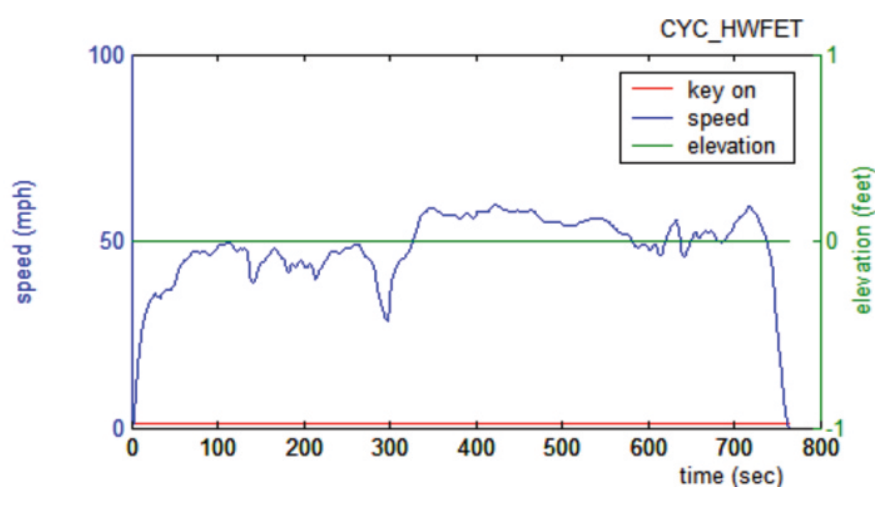

Fig.6: Speed-time graph representation of HWFET cycle

Table 3

Typical values for HWFET cycle

\begin{tabular}{lr}
\hline Cycle & HWFET \\
\hline Time(s) & 765 \\
Distance (miles) & 10.26 \\
Max. speed(mph) & 59.9 \\
Average speed $(\mathrm{mph})$ & 48.2 \\
Max. acceleration $\left(\mathrm{ft} / \mathrm{s}^{2}\right)$ & 4.69 \\
Max. deceleration $\left(\mathrm{ft} / \mathrm{s}^{2}\right)$ & -4.84 \\
Idle times(s) & 6 \\
Number of stops & 1 \\
\hline
\end{tabular}

\section{Powertrain modelling results}

Three hybrid-electric Powertrains namely Parallel, Combined (Series-Parallel or HSD) and Series hybrid were simulated using ADVISOR. Simulations were done using three cycles-UDDS, NEDC and HWFEC for each Powertrain. During UDDS cycle, parallel Powertrain had best fuel economy at $53.6 \mathrm{mpg}$ (table.4) because its fuel converter consumed the least fuel of 16,788 kj while Combined and Series hybrids consumed 18,605 kj and 25,484 kj respectively.

Table 4

Values obtained for UDDS cycle

\begin{tabular}{l|c|c|c}
\hline \multicolumn{4}{c}{ Urban Dynamometer Drive Cycle } \\
\hline Powertrain & $\begin{array}{l}\text { Fuel } \\
\text { econ.(mpg) }\end{array}$ & $\begin{array}{l}\text { Overall Sys. Eff. } \\
(\%)\end{array}$ & $\begin{array}{l}\text { Energy used } \\
(\mathbf{k j})\end{array}$ \\
\hline Parallel & 53.6 & 12.8 & 16,788 \\
Series & 35.3 & 8.6 & 25,484 \\
Combined & 48.4 & 11.4 & 18,603 \\
& & & \\
\hline
\end{tabular}


Since Series Hybrid rely entirely on fuel converter to charge the battery and power the generator, its poor fuel economy is expected. Combined hybrid on the other hand has more electrical components (extra generator plus complex power split device) than the Parallel configuration and will therefore consume more fuel. The highest overall efficiency of $12.8 \%$ for Parallel Hybrid indicates as the best Powertrain for this cycle. Similarly for NEDC drive cycle, Parallel configuration had best fuel economy of $51.8 \mathrm{mpg}$ with Series and Combined hybrids at $48.5 \mathrm{mpg}$ and $46.2 \mathrm{mpg}$ respectively (table 5). Combined hybrid operated predominantly with the engine power while Series and Parallel powertrains relied on both engine and motor power. This is proved by the fact that while Parallel and Series hybrid consumed 15,834 kj and 16,893 kj of energy respectively, Combined hybrid consumed the highest at $17,764 \mathrm{kj}$.

Table 5

Simulation values for NEDC cycle

\begin{tabular}{l|l|l|l}
\hline \multicolumn{5}{c}{ New European Drive Cycle } \\
\hline Powertrain & $\begin{array}{l}\text { Fuel } \\
\text { econ.(mpg) }\end{array}$ & $\begin{array}{l}\text { Overall Sys. Eff. } \\
(\%)\end{array}$ & \multicolumn{1}{l}{$\begin{array}{l}\text { Energy used } \\
(\mathbf{k j})\end{array}$} \\
\hline Parallel & 51.8 & 15.8 & 15,834 \\
Series & 48.5 & 13.5 & 16,893 \\
& & & 17,764 \\
Combined & 46.2 & 13.8 & \\
\hline
\end{tabular}

For the HWFET cycle, Combined Powertrain showed the most favourable fuel economy at $66.4 \mathrm{mpg}$ compared to Parallel and Series at $55 \mathrm{mpg}$ and 38.5 mpg respectively (table.6). Combined Powertrain consuming the least energy of 18,649 kj, (Series (32,194 kj) and Parallel $(22,528 \mathrm{kj}))$, proves that it relied predominantly on electric power to move the wheels.

Table 6

Simulation values for HWFET cycle

\begin{tabular}{l|l|c|l}
\hline \multicolumn{4}{c}{ Highway Fuel Economy Transport Cycle } \\
\hline Powertrain & $\begin{array}{l}\text { Fuel } \\
\text { econ.(mpg) }\end{array}$ & $\begin{array}{l}\text { Overall Sys. Eff. } \\
\text { (\%) }\end{array}$ & $\begin{array}{l}\text { Energy used } \\
\text { (kj) }\end{array}$ \\
\hline Parallel & 55 & 21 & 22,528 \\
Series & 38.5 & 14.7 & 32,194 \\
Combined & 66.4 & 23.7 & 18,649 \\
\hline
\end{tabular}

Combined Powertrain also exhibited the highest system efficiency of $23.7 \%$ compared to $21 \%$ and $14.7 \%$ for Parallel and Series respectively. This indicates that in spite of poor fuel converter efficiencies, combined hybrid is able to combine power from electric motor and fuel converter more efficiently.

\section{Conclusion}

During UDDS cycle Parallel Powertrain showed best fuel economy (53.6 mpg). Combined hybrid on the other hand has more electrical components (extra generator plus complex power split device) than the Parallel configuration hence had $48.4 \mathrm{mpg}$. The highest overall efficiency of $12.8 \%$ for Parallel Hybrid confirms it as the best Powertrain for this cycle. Similarly for NEDC drive cycle, Parallel configuration had the best fuel economy of $51.8 \mathrm{mpg}$ followed by Series and Combined hybrids at $48.5 \mathrm{mpg}$ and $46.2 \mathrm{mpg}$ respectively. Combined hybrid operated predominantly with engine power while both Series and Parallel powertrains relied on both engine and motor power. For HWFET cycle, Combined Powertrain showed the most favourable fuel economy at $66.4 \mathrm{mpg}$ compared to Parallel and Series at $55 \mathrm{mpg}$ and $38.5 \mathrm{mpg}$ respectively. Combined Powertrain relied predominantly on electric power to move the wheels. It also recorded highest system efficiency of $23.7 \%$ compared to $21 \%$ and $14.7 \%$ for Parallel and Series respectively. These findings indicate that in spite of poor fuel converter deficiencies, the Combined hybrid (power split device) is able to combine power from electric motor and fuel converter more efficiently. That is at higher speeds where both engine and battery power is required.

Combined hybrid is most suitable in terms of fuel economy and system efficiency. However for lower speeds where several stops are involved such as heavy traffic areas, Parallel hybrid stands favourite. This conclusion reveals that the choice of a hybrid Powertrain depends to a large extent on its application and intended purpose. Whereas combined hybrid is suitable for highway driving it is not the best for urban driving where several stops are expected at lower speeds.

\section{References}

Chachra, D., and Bhartendu, S., (2008). Drive Cycle Performance of a Double Planetary Gear Hybrid Electric Vehicle Transmission System, SAE Paper, No.2008-28-0037. 
Chottiner, E. J., Michael, B. L., Shailesh, S. K., Edmund, M.A.K., and Robert, S., (2002).Hybrid Powertrain with an Engine-Disconnecting Clutch, SAE Paper, No. 2002-01-0930.

EudeCezar, de O., and DecioCrisol, D. (2006). Modeling and Simulation of Small Hybrid, SAE Paper, No. 2006-01-2758.

Fuhs, A., (2009). Hybrid Vebicles and the Future of Personal Transportation, Broken Sound parkway NW, Taylor and Francis Group, LLC.

Hiltech (2006). Vebicle Hybrid Powertrain Architecture. Application note 2006-E/06/9.

Kimura, A., Ikuo, A., and Kenji, I., (2005). Development of Hybrid System for SUV, SAE Paper, No. 2005-010273.

Kluger, M. A., Don, S., and Edward A. B., (2001). A Dual-Use Hybrid Electric Command and Control Vehicle, SAE Paper, No. 2001-01-2775.

Kondo, K., Sumiko, S., and Michitaka,T., (2002). Development of an Electrical 4WD System for Hybrid Vehicles, SAE Paper, No. 2002-01-1043.

Meisel, J., (2006). An Analytic Foundation for the Toyota PriusTHS-II Powertrain with a Comparison to a Strong Parallel Hybrid-Electric Powertrain,SAE Paper, No. 2006-01-0666.

Miller, J.,(2004). Propulsion Systems for Hybrid Vebicles, Stevenage, the Institution of Electrical Engineers,U.K.
Senger, D., Randall, M. A. M. and Douglas, J. N., (1998). Validation of ADVISOR as a Simulation Tool for a Series Hybrid Electric Vehicle, SAE Paper, No.981133.

Singer-Englar, A., Kamisky,R.,Erickson,P., Frank,A., Allan, W., Bangar, C. ,Carde,C.,Dalal,A., Garas,D., Holdener,J., Meyr, N., and Nitta,C., (2005). Design and Development of a Parallel Hybrid Powertrain for a High Performance Sport Utility Vehicle, SAE Paper, No. 2005-01-3827.

Tate, E., Michael,D., Harpster,O., and Savagian,P.J., (2008). The Electrification of the Automobile: From Conventional Hybrid, to Plug-in Hybrids, to Extended-Range Electric Vehicles, SAE Paper, No. 2008-01-0458.

Toyota Motor Corp (2007). A Guide to Hybrid Synergy Drive.[Online]. Available at $<$ http://www.toyota.com> (Accessed 26 May, 2009).

UeokaKiyoshiro, Z. M., Kenya, M., Takeshi, I., Masatoshi, I., and Shuji, T., (2007). Hybrid System Development for High-Performance All Wheel Drive Vehicle, SAE Paper, No. 2007-01-0296.

Wikpe, B., Keith,R.,Cuddy, R. and Matthew,R., (1999). Using an Advanced Vebicle Simulator (ADVISOR) to Guide Hybrid Vebicle Propulsion System Development.[Online]. Available at < http://www.hev.doe.gov> (Accessed 26 May, 2009).

Yan-e, Z., Zhang, J. and Han, X.,(2008). Development of a High Performance Electric Vehicle with FourIndependent-Wheel Drives, SAE Paper, No. 200801-1829. 